\title{
PREVALENCE OF INTERNET ADDICTION AMONG MEDICAL STUDENTS: A STUDY FROM SOUTHWESTERN IRAN
}

\author{
Mehdi Sayyah ${ }^{1}$, Somayieh Khanafereh ${ }^{2}$ \\ ${ }^{1}$ Faculty Member of Education Development Centre, Ahvaz Jundishapur University of Medical Sciences, Ahvaz, Iran \\ 2Education Development Centre, Ahvaz Jundishapur University of Medical Sciences, Ahvaz, Iran
}

\section{SUMMARY}

Objective: In today's world, despite the numerous benefits, increasing demand for computer technology and the influence of widespread internet technology, many people, especially students, have faced impaired mental health and social relationships resulting from internet addiction; therefore, with regard to the contradictory results of preceding studies in the field of internet addiction, this study was designed to determine the prevalence of internet addiction in students of Ahvaz Jundishapur University of Medical Sciences.

Methods: This descriptive study was conducted on all students of Ahvaz Jundishapur University of Medical Sciences. For data collection questionnaire and demographic profile of internet addiction test was used.

Results: The results showed that internet addiction is common among university students $(t=23.286, p<0.001)$. Internet addiction is significantly different between males and females and more prevalent in the male users $(t=4.351, p=0.001)$. The prevalence of internet addiction in various categories was $1.6 \%$ normal, $47.4 \%$ mild, $38.1 \%$ moderate, and $12.9 \%$ severe. Our analysis also showed a significantly higher proportion of senior students with severe internet addiction (16.4\%) compared to junior students $\left(x^{2}=30.964 ; p<0.001\right)$.

Conclusion: Based on the findings of this study it can be concluded that there is a considerable internet addiction in medical students, and to prevent risks and complications, health considerations and proper treatments seem to be necessary.

Key words: mental health, addiction to Internet, university students

Address for correspondence: M. Sayyah, Imam General Hospital, Azadegan Avenue, Ahvaz, Iran. E-mail: sayah_bargard@Aol.com https://doi.org/10.21101/cejph.a5171

\section{INTRODUCTION}

Nowadays, internet addiction has been proposed to be included among psychological disorders in psychology and medicine; the fact that clinicians have reported cases of the disorder as a new form of addiction in recent years has attracted researchers in the field of psychology, psychiatry, sociology, and other scientific fields. Internet addiction is emerging in different cultures and societies. The prevalence of this problem has led to the identification of the causes, consequences and complications were followed up and investigated by experts and researchers (1).

For the first time the term internet addiction disorder was proposed by Goldberg to introduce and recognize people who show problems following the Internet use. He was the first person who formed a group to support internet addicts (2). Internet and computer addiction as a health problem has to be taken into consideration and it is classified as mental disorder (3). Internet is everywhere, at home, school, work and so on, and with the advent of the Internet and expanding its scope to all parts of the world, its technology formerly used only in the research centres until 1991, has found new and diverse applications (4). The growing demand for internet technology has become associated with mental health problems and unhealthy social relationships in many people $(5,6)$. Problematic excessive use of this technology and internet addiction have attracted increasing attention in the psychologists and other researchers (7).

Some researchers noted that excessive use of the Internet (overuse of the Internet for no specific purpose or pathological internet use or the overuse of certain online applications, and generalized pathological internet use) has negative impact on mental health, while students who pathologically and excessively use the Internet showed more mental problems compared with students who did not have such experience (8-11). In fact, levels of experience on the Internet is associated with the deterioration of mental health, and internet addiction affects a wide range of people directly and indirectly (12-14). Internet addiction is a global phenomenon with different prevalence levels ranging from 5 to $25 \%$ in the student populations of the United States, China, Korea, the UK, Australia, Taiwan, Japan, Eastern and Western Europe (11). Also in terms of gender, some studies have shown that up to two times less women have shown internet addiction than men $(9,13,15)$. Studies show that students, who suffer from internet addiction, feel lonely in terms of mental health, do not have the necessary skills in social relations, and have high vulnerability and low mental health $(3,4)$. 
Considering contradictory reports in the field of internet addiction (8-10), as well as the fact that students entering university become familiar with the technology and computer science and get more chance to excessively use the Internet, this study was designed to determine the prevalence of internet addiction in students of Ahvaz Jundishapur University of Medical Sciences.

\section{MATERIALS AND METHODS}

\section{Study Design and Population}

This is a descriptive study. The study population included all students of Ahvaz Jundishapur University of Medical Sciences. According to the latest information and statistics a total number of students were 6,342 individuals, 302 students were stratified by random sampling. The study was conducted in the 2015-2016 academic year.

\section{Data Collection}

Two questionnaires were used to collect the data, including demographic characteristics, such as age and gender, and internet addiction test. Internet addiction test questionnaire was developed by Young (16). This is the 20 questions self-assessment based on the Likert scale for measuring addiction to the Internet. Its ranking includes always (score 5), often (score 4), usually (score 3), sometimes (score 2), rarely (score 1), and never (score 0). The range of valid test scores is from 0 to 100 . Higher scores show more internet addiction. The level of internet addiction scores according to four categories include scores of 0 to 19 considered as normal, 20 to 49 considered as mild, 50 to 79 considered as moderate, and 80 to 100 considered as severe. Young confirmed its content and construct validity with the reliability test using Cronbach's alpha (0.91) that was calculated for the total sample (16).

\section{Functional Health Status Assessments}

Self-reported functional health status was described quantitatively using the Duke Health Profile (DUKE), which is a 17 -item generic questionnaire instrument appropriate for both patient and non-patient adult populations, designed to measure during a 1 -week time window (17). It comprises 11 scales with maximum score for each scale being 100 and minimum being 0 ; six scales, including physical health, mental health, social health, general health, perceived health, and self-esteem measure health function of which higher scores indicate better health. The remaining five scales, including anxiety, depression, anxiety-depression, and pain and disability, measure dysfunction with higher scores showing greater dysfunction. Both internal consistency (Cronbach's alpha) and temporal stability (test-retest) testing have supported reliability of the DUKE.

\section{Statistical Analysis}

For data analysis, descriptive statistics include percentage, mean, standard deviation, drafting tables and figures, and inferential statistics such as analysis of variance was used. Data was analyzed by the statistical package for social science, SPSS version
19.0 (SPSS Inc., Chicago, Ill., USA). Means, standard deviations, percentages, and the Student t-test and Chi-square test were performed to find relationships between variables. The $p<0.05$ was considered significant. The Kruskal-Wallis test was applied to compare Duke Health Profile values at different internet addiction.

\section{RESULTS}

The age range is $18-26$ years (mean age $=19.2$ years. $\mathrm{SD}=1.4$ ). Most of the respondents are within the age range of 18-20 years. Gender distribution showed that a vast majority (74.2\%) were females. Also, the majority of student $(64.3 \%)$ were in senior medical school (Table 1).

The prevalence of internet addiction in various categories was $1.6 \%$ normal, $47.4 \%$ mild, $38.1 \%$ moderate and $12.9 \%$ severe (Table 2).

The results showed that internet addiction is common among university students $(t=23.286, p<0.001)$. Our analysis also showed a significantly higher proportion of senior students with severe internet addiction (16.4\%) compared to junior students $\left(\chi^{2}=30.964 ; p<0.001\right)$ (Table 3).

The results also showed that internet addiction differs significantly between students who use the Internet $0-5$ hours per week and others (Fig. 1). The findings showed that internet addiction is different in males and females and more prevalent in the male users $(\mathrm{t}=4.351, \mathrm{p}=0.001)$

Considering the Duke Health Profile, results showed that internet addicts have poor mental and physical health score (Table 4). Our analysis showed no significant correlation between social health score, perceived health score, self-esteem score, pain and disability scores with internet addiction. Addicts had high anxiety, depression, and anxiety-depression scores (Table 4).

Table 1. Demographic distribution of respondents $(N=302)$

\begin{tabular}{|c|c|c|}
\hline Variables & Frequency & Percentage \\
\hline \multicolumn{3}{|l|}{ Age (years) } \\
\hline $18-20$ & 265 & 87.8 \\
\hline More than 20 & 37 & 12.2 \\
\hline \multicolumn{3}{|l|}{ Gender } \\
\hline Male & 78 & 25.8 \\
\hline Female & 224 & 74.2 \\
\hline \multicolumn{3}{|c|}{ Year of medical studies } \\
\hline Junior & 108 & 35.7 \\
\hline Senior & 194 & 64.3 \\
\hline
\end{tabular}

Table 2. Overall frequency distribution and prevalence of internet addiction among students $(N=302)$

\begin{tabular}{|l|c|c|c|}
\hline $\begin{array}{l}\text { Internet addiction } \\
\text { categories }\end{array}$ & Scores & $\mathbf{n}(\%)$ & $\begin{array}{c}\text { Overall } \\
\mathbf{n}(\%)\end{array}$ \\
\hline Normal & $0-19$ & $5(1.6)$ & $5(1.6)$ \\
\hline Mild & $20-49$ & $143(47.4)$ & \multirow{2}{*}{$297(98.4)$} \\
\cline { 1 - 2 } Moderate & $50-79$ & $115(38.1)$ & \multicolumn{2}{|c|}{$39(12.9)$} & \\
\cline { 1 - 3 } Severe & $80-100$ & &
\end{tabular}




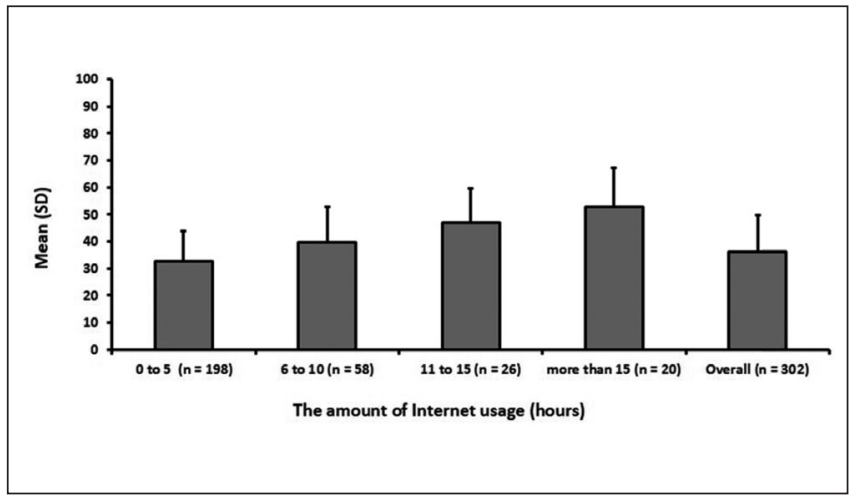

Fig. 1. Distribution of internet addiction in students based on the Internet use.

\section{DISCUSSION}

This study that aimed to assess the prevalence of internet addiction along with psychopathological factors in medical students showed that $76.5 \%, 21.2 \%$, and $0.7 \%$ of university students suffer from mild, moderate, and severe internet addiction, respectively. The results of this study were in line with the results of other researchers that noted a considerable deterioration in mental health of students following excessive and pathological use of the Internet $(6,8,10,11,18-20)$. They found that students who use the Internet pathologically when compared with students who did not have such experience show more mental problems.

Besides, the results of the present study showed that internet addiction follows different pattern in male and female students. Many other researchers also confirmed the gender differences in this context $(7-12,20)$. Other studies have shown that the prevalence of internet addiction in women was lower than in men (13, $21,22)$. It seems that internet addiction is more marked in male students compared to female students; however, the present study like other studies conducted around the world shows that students suffering from internet addiction have poorer mental health and social relationships. They feel fear, anxiety, depression, violence, loneliness, lack of identity, social anxiety, and other symptoms, and their social skills and coping are lower. Such people prefer

Table 3. Internet addiction among various age groups, gender and year of medical studies ( $N=297)$

\begin{tabular}{|c|c|c|c|}
\hline \multirow[b]{2}{*}{ Variables } & \multicolumn{3}{|c|}{ Internet addiction categories } \\
\hline & $\begin{array}{l}\text { Mild } \\
\mathrm{n}(\%)\end{array}$ & $\begin{array}{c}\text { Moderate } \\
\mathrm{n}(\%)\end{array}$ & $\begin{array}{c}\text { Severe } \\
\mathrm{n}(\%)\end{array}$ \\
\hline \multicolumn{4}{|l|}{ Age (years) } \\
\hline $18-20(n=260)$ & $128(49.2)$ & $101(38.8)$ & $31(11.9)$ \\
\hline More than $20(n=37)$ & $15(40.5)$ & $14(37.9)$ & $8(21.6)$ \\
\hline \multicolumn{4}{|l|}{ Gender } \\
\hline Male $(n=78)$ & $35(44.9)$ & $29(37.2)$ & $14(17.9)$ \\
\hline Female $(n=219)$ & $108(49.3)$ & $86(39.3)$ & $25(11.4)$ \\
\hline \multicolumn{4}{|l|}{ Year of medical studies } \\
\hline Junior $(n=108)$ & $54(50.0)$ & $46(42.6)$ & $8(7.4)$ \\
\hline Senior $(n=189)$ & $89(47.1)$ & $69(36.5)$ & $31(16.4)$ \\
\hline Total $(n=297)$ & $143(48.2)$ & $115(38.7)$ & $39(13.1)$ \\
\hline
\end{tabular}

Table 4. Internet use and psychopathology using Duke Health Profile $(N=297)$

\begin{tabular}{|c|c|c|c|c|c|}
\hline \multirow{2}{*}{ Duke Health Profile } & \multirow{2}{*}{$\begin{array}{c}\text { Mild* }^{*} \\
(n=143)\end{array}$} & \multirow{2}{*}{$\begin{array}{l}\text { Moderate* }^{*} \\
(n=115)\end{array}$} & \multirow{2}{*}{$\begin{array}{l}\text { Severe* }^{*} \\
(n=39)\end{array}$} & \multicolumn{2}{|c|}{ Kruskal-Wallis test } \\
\hline & & & & Chi-square & $\mathrm{p}$-value \\
\hline Physical health score & 60 & 90 & 40 & 42.285 & $<0.001$ \\
\hline Mental health score & 70 & 70 & 60 & 22.874 & $<0.001$ \\
\hline Social health score & 80 & 80 & 50 & 5.623 & 0.145 \\
\hline General health score & 20 & 25 & 16 & 38.251 & $<0.001$ \\
\hline Perceived health score & 40 & 40 & 40 & 3.987 & 0.079 \\
\hline Self-esteem score & 80 & 80 & 70 & 4.251 & 0.120 \\
\hline Anxiety score & 65 & 75 & 50 & 31.457 & $<0.001$ \\
\hline Depression score & 60 & 70 & 40 & 38.541 & $<0.001$ \\
\hline Anxiety-depression score & 70 & 65 & 55 & 30.675 & $<0.001$ \\
\hline Pain score & 45 & 45 & 50 & 2.853 & 0.998 \\
\hline Disability score & 90 & 90 & 90 & 1.635 & 0.972 \\
\hline
\end{tabular}

*Median scores 
computer and internet to social communication, consequently, they have fewer social relations with their friends, peers, family, spouses, and other people. Moreover, the results of the present study showed that the students that were more involved with the Internet were at a greater risk of addiction. In agreement with this finding, the other studies showed that increased work experience with the Internet is associated with poorer mental health and higher internet addiction $(7,9)$.

\section{CONCLUSION}

In today's world, internet technology is regarded as an effective tool, as long as it is used after an appropriate training to its full potential, but not to the extent that disrupts physical and mental health of individuals. Internet addiction as a new form of addiction in recent years has attracted researchers in the field of psychology, psychiatry, sociology, and fields of other sciences, it exists in various societies and cultures, and had an impact on all users of different gender and age. Based on the findings of this study it can be concluded that in the university students exists a considerable internet addiction, and to prevent health and social risks, health considerations and proper treatment seem to be necessary. In spite of the accounted unpleasant consequences of internet addiction, it is important to include media and internet literacy in general education at early ages such as children aged about 10 years and older. Comprehensive treatment may not be available or may be stigmatising. More useful and less expensive help would be free distribution of simple self-help tools. They might be sufficient especially in mild and moderate forms of addiction which clearly prevail. The number of severe cases of internet addiction was almost negligible in this population.

\section{Conflict of Interests}

None declared

\section{REFERENCES}

1. Cheng C, Sun P, Mak KK. Internet addiction and psychosocial maladjustment: avoidant coping and coping inflexibility as psychological mechanisms. Cyberpsychol Behav Soc Netw. 2015;18(9):539-46.

2. Shapira NA, Goldsmith TD, Keck PE Jr., Khosla UM, McElroy SL. Psychiatric features of individuals with problematic internet use. J Affect Disord. 2000;57(1-3):267-72.

3. Amichai-Hamburger Y, Ben-Artzi E. Loneliness and internet use. Comput Human Behav. 2003;19(1):71-80.
4. Anderson KJ. Internet use among college students: an exploratory study. J Am Coll Health. 2001;50(1):21-6.

5. Brenner V. Psychology of computer use: XLVII. Parameters of internet use, abuse and addiction: the first 90 days of the Internet Usage Survey. Psychol Rep. 1997;80(3 Pt 1):879-82.

6. Stefanescu C, Chele G, Chirita R, Chirita V, Ilinca M. The relationship between development identity and internet addiction. Eur Psychiatry. 2007;22 Suppl 1:S200.

7. Yen JY, Ko CH, Yen CF, Wu HY, Yang MJ. The comorbid psychiatric symptoms of Internet addiction: attention deficit and hyperactivity disorder (ADHD), depression, social phobia, and hostility. J Adolesc Health. 2007;41(1):93-8.

8. Treuer T, Fabian Z, Furedi J. Internet addiction associated with features of impulse control disorder: is it a real psychiatric disorder? J Affect Disord. 2001;66(2-3):283.

9. Chou C, Hsiao MC. Internet addiction, usage, gratification, and pleasure experience: the Taiwan college students' case. Comput Educ. 2000;35(1):65-80.

10. Yellowlees PM, Marks S. Problematic internet use or internet addiction? Comput Human Behav. 2007;23(3):1447-53.

11. Li SM, Chung TM. Internet function and internet addictive behavior. Comput Human Behav. 2006;22(6):1067-71.

12. Kim K, Ryu E, Chon MY, Yeun EJ, Choi SY, Seo JS, et al. Internet addiction in Korean adolescents and its relation to depression and suicidal ideation: a questionnaire survey. Int J Nurs Stud. 2006;43(2):185-92.

13. Kim WJ, Yang JC, Choi Y. Relationship between adolescent internet addiction tendency and family environment. Chonnam Med J. 2002;38(3):235-41.

14. Griffiths M. Internet abuse in the workplace: issues and concerns for employers and employment counselors. J Employ Couns. 2003;40(2):8796.

15. Wang WEI. Internet dependency and psychosocial maturity among college students. Int J Hum Comput Stud. 2001;55(6):919-38.

16. Young KS. Internet addiction: the emergence of a new clinical disorder. Cyber Psych Behavior. 2009;1(3):237-44.

17. Schuntermann MF. The Duke Health Profile (DUKE). Rehabilitation (Stuttg). 1997;36(1):I-XIV. (In German.)

18. Davis RA. A cognitive-behavioral model of pathological Internet use. Comput Hum Behav. 2001;17(2):187-95.

19. Lavin M, Marvin K, McLarney A, Nola V, Scott L. Sensation seeking and collegiate vulnerability to internet dependence. Cyberpsychol Behav. 1999;2(5):425-30.

20. Bahrainian SA, Alizadeh KH, Raeisoon MR, Gorji OH, Khazaee A. Relationship of Internet addiction with self-esteem and depression in university students. J Prev Med Hyg. 2014;55(3):86-9.

21. Shepherd RM, Edelmann RJ. Reasons for internet use and social anxiety. Personal Individ Diff. 2005;39(5):949-58.

22. Weidman AC, Fernandez KC, Levinson CA, Augustine AA, Larsen RJ, Rodebaugh TL. Compensatory internet use among individuals higher in social anxiety and its implications for well-being. Personal Individ Diff. 2012;53(3):191-5.

Received July 18, 2017

Accepted in revised form October 17, 2019 